\title{
FAMILY-CENTRED UNEMPLOYMENT IN FOUR \\ DISADVANTAGED AREAS IN AUSTRALIA
}

\author{
Kathy Tannous, Ian Caddy and Dennis \\ Mortimer
}

\author{
University of Western Sydney, Parramatta \\ New South Wales, Australia
}

\begin{abstract}
Australia's unemployment rate is one of the lowest of any OECD country. However, for families with children, partnered and lone parents, the rate of unemployment and most importantly joblessness is one of the highest at $14.7 \%$ and $46 \%$ respectively in 2009. This research project aims to better understand problems and issues that face families in which there is at least one family member who is long-term unemployed. The study focuses on the experiences on jobless families in four disadvantaged areas in Australia, with three surveyed at the beginning of the global financial crisis (GFC) and one area to be studied post the GFC. This paper will present methodologies of quantitative survey of long term jobless coupled with qualitative data obtained from the conduct of focus groups and interviews; and findings of the major contributors of the jobless families' current circumstances including lack of basic skills and qualifications, low levels of formal education and deep lack of confidence and motivation..
\end{abstract}

\section{Introduction}

Australia's unemployment rate is one of the lowest of any country in the Organisation for Economic Co-operation and Development (OECD) at $5.1 \%$ on a person basis as at January 2011 (ABS, 2011). On a historical basis, this rate is at very low levels and current public discussions are centred around the issue of labour force shortage. The unemployment rate measure is determined by the Labour Force survey undertaken by the Australian Bureau of Statistics (ABS). The ABS uses the international definition of unemployment that requires the satisfaction simultaneously of three criteria: without work; actively seeking work; and currently available for work. Without work criterion refers to total lack of work that is not in paid or self employment and not have undertaken work not even for one hour. Actively seeking work requires that a person must have done something specific to obtain work such as application made, placing an ad and so on. Availability criterion is a test of readiness to start work with people must be available to start work in the reference period (ABS, 2007). For persons who are not employed and are not actively looking for work or are actively looking for work but are not available to start work in the reference week are counted by the ABS as "not in the labour force" (ABS, 2007b) .

Jobless is a term that is increasingly being used encompassing those persons who are unemployed and looking for work and those that are not in the labour force and not actively looking for work (Whiteford, 2009). This term is extended to jobless families; families whose parent/s are jobless and have dependent children aged under 15 years. Jobless families are noteworthy to study as parental joblessness has been identified to have disadvantages on children including poor health, disability, and low educational attainment (Whiteford, 2009) and negative impacts by putting children at higher risk of mental health and developmental problems (Gregory, 1999). The impact on children's behavioural and emotional problems of living in a jobless family has been estimated to increase by between 7 to 13 percentage points, depending on the measure (Taylor, Edwards and Gray, 2010).

Section 2 will present background on this paper then followed by details of the methodology for the study in section 3. Section 4 will present some of the initial findings and finally section 5 will present the initial conclusions and future research ideas.

\section{Background}

The global financial crisis of 2008-09 has seen a deterioration of the labour market conditions around the world. In Australia, the unemployment rate rose by 1.3 percentage points to $5.6 \%$, much less than the rises experienced by other OECD countries. The full impact is still yet to be felt on the long-term unemployed as it tends to lag other changes in the labour market by many months (ABS, 2010). Furthermore, long-term unemployment is not evenly distributed throughout the metropolitan area or indeed outer regional areas; but is often concentrated in social and economically disadvantaged suburbs (Taylor, Edwards and Gray, 2010). 
The importance of establishing effective programs for long-term unemployed has been highlighted in a recent report commissioned by the Social Inclusion Unit, namely Family Joblessness in Australia (Whiteford, 2009a) which identified jobless families as among those who are more likely to face significant and long-term difficulties with respect to social inclusion. For example, in the executive summary, Whiteford (2009a, p. 4) makes the following comments:

While Australia has a high overall level of employment compared to other developed countries in the OECD, it also has one of the highest levels of joblessness among families with children of all rich countries. Identifying the factors behind this poor performance can contribute to improving policies to promote social inclusion.

This fact, among others, has resulted in the current government's conviction that supporting these and other vulnerable families 'to take action to improve their economic circumstances' should be a prime concern for both government and community (Commonwealth of Australia, 2008, pp. 1-4). As well, the continued very high rates of people not in the labour force, the focus then needs to consider what the underlying causes of job finding, that is the supply of labour and their efforts or barriers, coupled with the needs of the firms seeking employees (Gomme, 2005).

Related to this concern about social exclusion by jobless families, a study in early 2009 was undertaken in three of the most socially and economically disadvantaged suburbs in Australia one within each state of Victoria, Queensland and South Australia. The study was embarked upon in the depth of the Global Financial Crisis with much public debate on the potential impact of the Crisis on the economy and unemployment (Whiteford, et al., 2009). Comments made by the most senior policy maker were that Australia "faced the grimmest set of global economic conditions since the Great Depression" (Swann, 2010). The Australian Treasury Department had forecasted that the unemployment rate was to peak at $8.5 \%$ but instead it had peaked at 5.8\% (Swann, 2010).
The 2010 study aimed to replicate and extend the earlier study. There are two main reasons for replicating the 2009 study. First, the study is broadened to include a New South Wales suburb that has similar experiences of disadvantage. The suburbs located in a western Sydney local government area, according to the 2006 population census data, have significant social and economic disadvantage. They have similarities with suburbs to those covered in the earlier study. Furthermore, the fact that the 2009 study was completed during the dark days of the global financial crisis, it will be interesting to see whether Australia's quite dramatic recovery, and the Federal Government's stimulus package, has had any impact for families that may have been jobless prior to the crisis emerging. The other aspect of the 2010 study is to use the theory of disengagement to identify if jobless families have characteristics of self-efficacy, persistence and optimism in terms of attempts to deal with their current circumstances (Caddy, Mortimer and Tannous, 2010) or whether, as was noted in the earlier study, that disengagement itself presents a significant obstacle or barrier to re-entering the workforce (either on a casual, part-time or full-time basis).

\section{Methodology}

The four locations in Australia that were chosen for this study were disadvantaged by most indicators. There were high populations of sole parent families, people from culturally and linguistically diverse backgrounds, areas of high Indigenous populations, people with disabilities and people with low labour force participation. For the four research sites, the percent of persons not in the labour force and unemployed is much higher than the Australian average at rates of $58 \%, 55 \%, 39 \%$ and $38 \%$ not in the labour market in site $3,1,2$, and 4 respectively as compared to $35 \%$ Australian average. But as well, the participation rate, calculated as the percent of people employed and unemployed divided by the number of people aged 15 and over, is evidently lower than the Australian rate ${ }^{1}$.

The methodology used is collection of primary qualitative data from jobless individuals as well as stakeholders who have contact with these individuals. Consultation was undertaken with community stakeholders, local and state

Table 1:Population aged 15 years by labour market classification* (\% of persons), 2006

\begin{tabular}{lccccc}
\hline Labour market classification & $\begin{array}{c}\text { Site 1 } \\
\text { (Victoria) }\end{array}$ & $\begin{array}{c}\text { Site 2 } \\
\text { (Queensland) }\end{array}$ & $\begin{array}{c}\text { Site 3 (South } \\
\text { Australia) }\end{array}$ & $\begin{array}{c}\text { Site 4 (New } \\
\text { South Wales) }\end{array}$ & Australia \\
\hline Employed full-time & $24.2 \%$ & $36.8 \%$ & $23.8 \%$ & $39.7 \%$ & $39.2 \%$ \\
Employed part-time & $10.5 \%$ & $14.2 \%$ & $9.3 \%$ & $13.4 \%$ & $18.0 \%$ \\
Employed away from work & $1.4 \%$ & $1.8 \%$ & $0.8 \%$ & $2.0 \%$ & $2.3 \%$ \\
Employed hours not stated & $1.7 \%$ & $2.2 \%$ & $2.2 \%$ & $2.1 \%$ & $1.7 \%$ \\
Unemployed & $7.1 \%$ & $5.6 \%$ & $5.6 \%$ & $4.7 \%$ & $3.4 \%$ \\
Not in the labour force & $55.1 \%$ & $39.4 \%$ & $58.3 \%$ & $38.0 \%$ & $35.4 \%$ \\
\hline \multicolumn{1}{c}{ Participation Rate } & $44.9 \%$ & $60.6 \%$ & $41.7 \%$ & $62.0 \%$ & $64.6 \%$ \\
\hline
\end{tabular}

Source: ABS (2007a)

* Total population was calculated by adding total labour force plus the number of persons not in the labour force. 
government, local non-government organisations, employers and service providers. For three of the four sites, unemployed families were invited to participate in focus groups and/or one-to-one interviews. The families were randomly selected from a list of income support recipients who had dependent children and were unemployed for at least 12 months. Telephone contact was made with the primary listed carer inviting them to participate in the study by attending one of two focus groups that was held in each study site. A small payment of $\$ 50$ gift voucher was made to each participant in recognition of the time given and costs incurred. Additional in-depth interviews were conducted with family members in each location receiving a small payment of $\$ 50$. The aim of the additional one-to-one interviews was to identify in greater depth specific needs of that family unit (Tannous and Whiteford, 2009).

For the fourth site, in NSW, service providers, defined as any service that supports or is in contact with jobless individuals in that state suburb, were contacted and participants were sourced from their client list; researchers were also invited to present their study to potential participants at pre-organised service provider events. Again a small payment of $\$ 30$ gift voucher was made to each participant in recognition of the time given and any costs incurred. The smaller payment amount was due to different funding source obtained for this fourth site.

Overall, seven focus groups were held with families with 44 family participants and 75 consultations with service providers were made. Some of the challenges in sourcing jobless individuals for the NSW site was that the researchers were dependent on service providers to identify their clients and seek their consent in order for their details to be forwarded on. This was to keep within the approved ethics guidelines.

\section{Findings}

Many of the problems identified were common across these areas. Transport was a common problem, with public transport being inadequate, particularly outside normal working hours, for shift workers. Many households had no one with a driver's licence or no (driveable) cars. Journey to work times made employment outside the area difficult for parents and people with disabilities.

The biggest issue you have here is the mobility for young people, insufficient transport; the recreational centres are out in the middle of nowhere. (Service provider).

There is no bus service on Sundays. It stops people from going to the football and taking their families out because there are no buses to get people to the trains on their side or anything. (Resident)

It costs money to get a licence - to hire driving instructors, sit the tests and so on. It also costs a lot of money to run a car... They have built all this infrastructure in the area but there is no way to get there. (Service provider)

This finding supports the quantitative data from the Australian 2006 General Social Survey that found that jobless households with children were less likely to have access to a motor vehicle to drive and cannot get to, or often has difficulty getting to, the places needed (due to transport difficulty) when compared with similar households with employed adults, $74 \%$ and $10 \%$ compared with $96 \%$ and $2 \%$ respectively (ABS. 2007c). Access to transportation that is reliable and low cost was identified by Barry (2002) to be crucial factor for social inclusion for low income individuals. "In its absence, the participation of those who cannot afford to run a car or hire a taxi will be severely limited" (Barry, 2002: 16).

Computer and internet access and skills were identified as lacking. Those who could obtain computers often could not afford the internet, and for many families the children were able to use the computer but the adults had no or low skills. These skills are fundamental to social inclusion, access to information and communication and employment prospects. For seeking employment or even to find out about available positions, more and more demanders of labour are using the world wide web or online applications through their own websites or alternative through providers such as seek.com. A number of the jobless alluded to the general availability of computers at libraries and the job network providers. However, the barriers of needing to travel there, high demand for these resources and lack of available support on how to use the computer and internet.

They do [have internet services] but it's always booked out... The more facilities and the more time would help a lot, because 45 minutes is not enough to stay on the internet, you just get the feel of it and then you have to get off. (Resident)

This supports the findings by the ABS in 2006 that found that jobless persons with children under 15 years that are one parent family that $53.7 \%$ and $34.5 \%$ had used the computer at home in the last 12 months and had accessed the internet at home in the last 12 months respectively. This compares with similar one parent family with employed adult had $77.4 \%$ and $65.0 \%$ using the computer and accessing the internet respectively (ABS, 2007c).

A number of the jobless and the service providers had identified low levels of formal education, and literacy and language as barriers to the labour market. Their experiences of school, especially for those with language and literacy problems, often make them reluctant to engage in further training and education.

You have got a lot of non English speaking people in this area too which would be a bit of a barrier as well. A lot of the people that are left on the case loads now don't speak English (Service provider).

Training, work experience for a lot of them, some of the migrants that you need have great qualifications 
from overseas ... for example was an engineer just came to Australia and people could be intimidated by their overseas qualifications so there is no recognition of their learning. (Service provider)

Many have are illiterate in English but also in their mother-tongue... most of what they need to do to get a job requires them to fill out some form (Service provider).

Similar findings were obtained by Kenny, Mansouri and Spratt (2005) that external barrier to the promotion of bridging social capital, such as employer discrimination in work, and limitations to culturally sensitive community services and resources.

A common reason for individual or family movement to the four sites is to access public housing that draws upon other circumstantial issues the individual may face.

That doesn't come because they are lazy it is there because it is a kind of suburb that attracts poor people and people who are part of a cycle of generated poverty, people who come here because of public housing so they are poor, people who use to mingle with other people who are poor and they maybe don't have many role models that they can connect to. (Service provider)

The biggest challenge that we have to deal with, domestic violence is one, socio economic issues, parenting is another issue, a lot of families we come across are dysfunctional, and a lack of parenting skills available hence the kids are brought up in that cycle. (Service provider)

Poor levels of education for many of the research participants were seen as important barriers to employment and training. As one service provider summed up the environment as one where increasingly there are jobless who go from one training course to another but may never be employed given their lack of experience or work readiness.

This is supported by analysis of the ABS confidentialised unit record file for Household Income and Income Distribution (2007-2008) whereby a jobless variable was created by combining those that are long-term unemployed (i.e. unemployed for 12 months or more) plus those that are not in the labour force (excluding those that are studying full time or permanently unable to work). The data shows that jobless persons with dependents aged less than 15 years of age were less educated with $27 \%$ and $24 \%$ having year 10 and year 12 respectively as the highest level of education attained. This compares with people who are not jobless $20 \%$ and $21 \%$ having Bachelor Degree and Certificate III/IV respectively as the highest education level attained (Table 2) $(\mathrm{ABS}, 2009 \mathrm{a})^{2}$.

Parents have an impact on their children's continued involvement in the school system and future engagement or lack of engagement with the labour market. A number of individuals indicated the important role which parents or guardians play in relation to setting the fundamental guidelines and encouragement structures and employment paths.

In terms of chronic unemployment with the people who would never become employed in the formal employment process even if you have full employment they would never get a job, a lot of those are basically people who drop out of life at very early teens or pre teens drop out of school and society just letting them allow it to happen. (Service provider)

This is supported by findings from the ABS Survey of Childhood Education and Care that found that there is

Table 2: Highest Education Level Attained by Jobless Status, Australia, 2007-08

\begin{tabular}{|lcccc||}
\hline Level of highest educational attainment & $\begin{array}{c}\text { Not } \\
\text { jobless }\end{array}$ & $\begin{array}{c}\text { Jobless no } \\
\text { dependents }\end{array}$ & $\begin{array}{c}\text { Jobless with } \\
\text { Dependents }<15\end{array}$ \\
\hline Postgraduate Degree, Graduate Diploma/Graduate Certificate & $8.2 \%$ & $2.5 \%$ & $0.4 \%$ & $6.6 \%$ \\
Bachelor Degree & $20.4 \%$ & $7.5 \%$ & $3.5 \%$ & $16.7 \%$ \\
Advanced Diploma/Diploma & $9.8 \%$ & $6.8 \%$ & $4.8 \%$ & $8.9 \%$ \\
Certificate III/IV & $21.3 \%$ & $14.2 \%$ & $11.0 \%$ & $19.3 \%$ \\
Certificate I/II & $0.5 \%$ & $0.2 \%$ & $0.8 \%$ & $0.5 \%$ \\
Certificate not further defined & $0.5 \%$ & $2.0 \%$ & $1.1 \%$ & $0.9 \%$ \\
Year 12 & $14.5 \%$ & $8.1 \%$ & $24.1 \%$ & $13.1 \%$ \\
Year 11 & $5.8 \%$ & $3.5 \%$ & $11.0 \%$ & $5.4 \%$ \\
Year 10 & $12.1 \%$ & $19.0 \%$ & $26.6 \%$ & $14.3 \%$ \\
Year 9 & $3.5 \%$ & $10.9 \%$ & $10.0 \%$ & $5.5 \%$ \\
Year 8 or below & $3.2 \%$ & $25.2 \%$ & $6.6 \%$ & $8.9 \%$ \\
\hline Total Number & $5,821,136$ & $2,063,104$ & 196,431 & $8,080,671$ \\
\hline Source: ABS Household Income and Income Distribution $2007-2008$ & & & & \\
& & &
\end{tabular}


significant difference in the provision of informal learning for children in families that have at least one parent employed. Informal learning is defined as parental involvement in learning activities last week by way of reading a book or telling a story; watching $\mathrm{TV}$, videos or DVDs, assisted with drawing and so on. Children in families with at least one employed parent were more likely $(93 \%)$ to have a parent actively involved with them in informal learning activities than if they had no employed parent ( $84 \%$ in couple families and $88 \%$ in one parent families). For children in couple families with no parents who were employed, of those that were read to or told them stories, 56\% participated in these informal learning activities with a parent every day compared with $68 \%$ of children in families where both parents were employed (ABS, 2009b).

For a number of interviewed residents and service providers in the four sites, details were provided that for many jobless individuals they described that for many they either choose not to access or are unable of community or government services. This was identified broadly by participants irrespective of their cultural focus or geographical location.

[Migrant families] that not only are they isolated, don't understand the system, in a new culture, often have a very large number of children, often don't have a partner, traumatized by grief of what they have seen or experienced but they might experience racism, a lot of them have mental health issues related to all of those things and it is hard to disentangle what is going on, some of them don't have mental health issues but struggling in gaining a sense of direction and don't know how to recover. (Service provider)

They consider some services as a threat to their cultural and religious views. So then it all comes back to having a culturally appropriate program and it is all about what we have considered, which is educating the parents first and that will then create a discussion within the family. (Service Provider)

Any person who may struggle academically or cannot speak the same language as the people around them, or even those who were born in Australia who haven't had the sufficient education or still can't speak proper English or have been equipped with the interpersonal skills will always struggle no matter where they are, not just with Government services. (Service provider)

This was identified by Mansour and Makhoul (2004) in their study that only $49 \%$ of respondents had access government services and $24 \%$ did not access these services as they did not know what existed. Similar findings were noted in other countries. In the United States, the Center on Budget and Policy Priorities in Washington estimates that in an average month in 2006, there were around one million single others who neither had jobs nor were receiving cash public assistance nor were living with someone who worked or received income support. Many turn to informal support givers for assistance such as family, friends and other associates (Henly, Danziger and Offer, 2003).

In all areas people interviewed had long absences from employment either because of parenting, disability or long-term unemployment. There was also a strong incidence of mental illness, such as anxiety and depression, drug and alcohol abuse, generally poor health and poverty reduced their employability and job readiness. There was a deep lack of confidence, hope, trust and motivation. Poor motivation and lack of desire to be employed was noted strongly by many different service providers. It should be noted that these characteristics are similar to those under the theory of disengagement to categorise highly disengaged people. Some explained this by reference to the home environment and general attitudes in the community. The lack of motivation coincided to inadequate role modelling and encouragement resulting from lack of leaderships and "learning by example" experiences sourced from family and community members.

You find most young boys who I have spoken to have no motivation and no interest at all and I don't mean to pin point but there is no one out there to push them. They don't have a parent or mentor who lifts their spirits and makes them want to get a job or accomplish anything (Resident)

They will always gravitate to a negative thought. We have some young guys who have tried to apply ... and they have said we tried and failed so they're not going to give it to us. (Service provider)

\section{Conclusion and Future Research}

From the discussion above and the findings presented further research into jobless and jobless families with dependent children must continue to occur in Australia despite the fact that the public focus has moved away with the strength of the economy and low official unemployment rates. This is particularly so as many researchers demonstrate conclusively that joblessness has an impact beyond the person but also on the children that are living in a jobless family. The needs and barriers to participation in the labour market needs to be examined in more depth particularly in more detail by certain characteristics, such as the young aged, recent migrants, single parents who have been absent for long periods of time. 
National University

http://econrsss.anu.edu.au/pdf/DP406.pdf

\section{References}

Australian Bureau of Statistics (2011), Labour Force Australia (No. 6202.0), Australian Government, Canberra.

Australian Bureau of Statistics (2009a), Household Income and Income Distribution, Australia, 200708, Confidentialised Unit Record Files, Australian Government, Canberra.

Australian Bureau of Statistics (2009b), Childhood Education and Care, June 2008, Australian Government, Canberra.

Australian Bureau of Statistics (2007a), 2006 Census QuickStats, Australian Government, Canberra.

Australian Bureau of Statistics (2007b), Labour Statistics: Concepts, Sources and Methods (No. 6102.0.55.001), Australian Government, Canberra.

Australian Bureau of Statistics (2007c), General Social Survey: Summary Results, Australia, 2006, (No. 4159.0), Australian Government, Canberra.

Australian Bureau of Statistics (2006), How Australia Takes a Census Australia 2006, (No. 2903.0), Australian Government, Canberra.

Barry, B., (2002), 'Social exclusion, social isolation and the distribution of income'. In J.Hills, J. Le Grand \& D. Piachaud, (eds.) Understanding Social Exclusion, Oxford, Oxford University Press.

Barry, B. (1998), Social exclusion, social isolation and the distribution of income', Centre for Analysis of Social Exclusion, London School of Economics, CASE paper 12, August 1998.

Caddy, I., Mortimer, D., and K. Tannous (2010), Can the theory of disengagement be applied to the longterm unemployed?, Pacific Employment Relations Assocation 10th Annual Conference 2010, 15-18 November 2010, Gold Coast, Queensland.

Gomme, P. (2005), Accounting for the jobless recoveries, Federal Reserve Bank of Cleveland Economic Commentary, August 1, 2005.

Gregory, R.G. (1999) 'Children and the changing labour market: joblessness in families with dependent children' Discussion Paper, a paper presented to the conference, 'Labour Market Trends and Family Policies: Implications for Children', 14-15 July, Centre for Economic Policy Research, Research School of Social Sciences, Australian
Henly, J. R., S. K. Danziger and S. Offer (2003) 'The contribution of social support to the economic status and daily coping of former and current welfare recipients'

http://www.fordschool.umich.edu/research/pdf/hen lydanzoffer.pdf

Kenny, S., Mansouri, F., and P. Spratt (2005), Arabic Communities and Well Being: Supports and Barriers to Social Connectedness, Centre for Citizenship and Human Rights, Deakin University.

Mansouri, F. And Carol Makhoul (2004), ArabAustralians in Victoria, Needs Assessment and Capacity Building, Centre for Citizenship and Human Rights, Deakin University.

Miranti, R., Harding, A., Ngu, V.Q., McNamara, J. and R. Tanton (2008), Children with jobless parents: National and small area trends for Australia in the past decade, National Centre for Social and Economic Modelling, 37th Annual Conference of Economists, Gold Cost, 30 September - 3 October 2008 .

O’Regan, C., Jobless Families (feature articles)(2009), Australian Labour Market Statistics, Jan 2009, Catalogue No. 6105.0.

Swann, W. (2010), Budget Speech 2010-11, delivered on 11 May 2010 on the Second Reading of the Appropriation Bill (No. 1,) 2010-11, Australian Treasury, http://www.budget.gov.au/201011/content/speech/html/speech.htm

Tannous, W.K. and P. Whiteford (2009), Family-centred research on employment for jobless families in three disadvantaged areas in Australia, Labour Underutilisation, Unemployment and Underemployment, Proceedings Refereed Papers, 11th Path to Full Employment Conference and 16th National Conference on Unemployment, 3-4 December 2009, The University of Newcastle (pg. 281-289).

Taylor, M., Edwards, B. And M. Gray (2010), Background Paper: Unemployment and the wellbeing of children aged 5-10 years, The Benevolent Society and the Australian Institute of Family Studies.

Whiteford, P. (2009), Family Joblessness in Australia, Social Inclusion Unit of the Department of the Prime Minister and Cabinet, Jan 2009.

Whiteford, P., Tannous, W.K., Shaver, S., Perry, J., Thompson, D., Griffiths, M., Heese, K., and T. Mourad (2009), Family-Centred Employment 
Project (Jobless Families): Broadmeadows (Victoria), Goodna (Queensland) and Mansfield Park (South Australia), Report for the Commonwealth Department of Education, Employment and Workplace Relations, Social Policy Research Centre, University of New South Wales, March 2009.

\section{Notes}

${ }^{1}$ In the compilation of the not in the labour force, it is the persons aged 15 plus and are not working as per their "No" answers to question 34 ("last week, did the person have a full-time or part-time job of any kind"), question 46 ("did the person actively look for work at any time in the last four weeks?"), question 47 ("If the person had found a job, could the person have started work last week?). ABS (2006)

${ }^{2}$ Data was derived from the Confidentialised Unit Record File for the Australian Bureau of Statistics (ABS)

Household Income and Income Distribution 2007-08.

Data was merged from the elements of the personal level data base together with household level database by using the household reference person in the personal level variable "position in the household" and merged with household data base with the linking variable being the unique household identifier number. The main reason for undertaking this was that the personal level database did not contain information on the number of children in age groups while the household level data base did. By using the both data bases, identification was made of those that are jobless defined as long term unemployed (i.e.

unemployed for 12 months or more) plus those not in the labour force excluding those that are studying full time or permanently unable to work. 